\title{
Comparison of characteristics from White- and Black-Americans with venous thromboembolism: A cross-sectional study
}

\author{
John A. Heit, ${ }^{1 *}$ Michele G. Beckman, ${ }^{2}$ Paula L. Bockenstedt, ${ }^{3}$ Althea M. Grant, ${ }^{2}$ Nigel S. Key, ${ }^{4}$ \\ Roshni Kulkarni, ${ }^{5}$ Marilyn J. Manco-Johnson, ${ }^{6}$ Stephan Moll, ${ }^{4}$ Thomas L. Ortel, ${ }^{7}$ and Claire S. Philipp ${ }^{8}$ for \\ the CDC Thrombosis and Hemostasis Centers Research and Prevention Network
}

\begin{abstract}
When compared with Whites, Black-Americans may have a $40 \%$ higher incidence venous thromboembolism (VTE) incidence. However, whether other VTE characteristics and risk factors vary by race is uncertain. To compare demographic and baseline characteristics among White- and Black-Americans with VTE, we used data prospectively collected from consecutive consenting adults enrolled in seven Centers for Disease Control (CDC) Thrombosis and Hemostasis Centers from August 2003 to March 2009. These characteristics were compared among Whites $(n=2002)$ and Blacks $(n=395)$ with objectively diagnosed VTE, both overall, and by age and gender. When compared with Whites, Blacks had a significantly higher proportion with pulmonary embolism (PE), including idiopathic PE among Black women, and a significantly higher proportion of Blacks were women. Blacks had a significantly higher mean BMI and a significantly lower proportion with recent surgery, trauma or infection, family history of VTE, and documented thrombophilia (solely from reduced factor V Leiden and prothrombin G20210A prevalence). Conversely, Blacks had a significantly higher proportion with hypertension, diabetes mellitus, chronic renal disease and dialysis, HIV, and sickle cell disease. When compared with White women, Black women had a significantly lower proportion with recent oral contraceptive use or hormone therapy. We conclude that Whites and Blacks differ significantly regarding demographic and baseline characteristics that may be risk factors for VTE. The prevalence of transient VTE risk factors and idiopathic VTE among Blacks appears to be lower and higher, respectively, suggesting that heritability may be important in the etiology of VTE among Black-Americans. Am. J. Hematol. 85:467-471, 2010. () 2010 Wiley-Liss, Inc.
\end{abstract}

\section{Introduction}

Most epidemiologic studies of venous thromboembolism (VTE) risk factors have been conducted within White-American and -European populations [1-4]. However, when compared with Whites, Black-Americans appear to have a higher risk for $[5,6]$ and incidence of VTE [7-10]. Two single-nucleotide polymorphisms, factor $V$ Leiden (G1691A) and prothrombin G20210A, have been identified as risk factors for deep vein thrombosis (DVT) and pulmonary embolism (PE) in Europeans and White-Americans, [11-16] but not Black-Americans $[6,17,18]$. We hypothesized that the apparent higher VTE incidence among Blacks might be due to an increased prevalence of known VTE risk factors. To test this hypothesis, we compared demographic and baseline clinical characteristics from White- and Black-Americans with objectively diagnosed VTE who were seen in one of the seven CDC Thrombosis and Hemostasis Research and Prevention Network centers.

\section{Methods}

\section{Study setting, population, and design}

The study setting was the seven centers (the University of Michigan Hemophilia and Coagulation Disorders Program, Ann Arbor, MI; the Thrombophilia Program, UNC, Chapel Hill, NC; the Michigan State University Comprehensive Center for Bleeding Disorders, East Lansing, $\mathrm{Ml}$; the Wayne State University, Detroit, MI; the Mountain States Regional Hemophilia and Thrombosis Center, Aurora, CO; the Duke Hemostasis and Thrombosis Center, Durham, NC; and the New Jersey Regional Hemophilia Program, UMDNJ-Robert Wood Johnson University Hospital, New Brunswick, NJ) within the CDC Thrombosis and Hemostasis Centers Research and Prevention Network [19] with substantial numbers of Black-American patients with VTE. Patients and/or their families attending one of the seven centers for medical care, or seen as an inpatient consult or referral, were approached by local center staff for study participation regardless of age, gender, or race. For consenting patients, study participation consisted of center staff completion of a standardized data collection form for the initial and all subsequent visits. In the case of pediatric patients, consent was obtained from the parent or legal guardian as well as an assent for children older than 7 years of age. Data were entered into a web-based registry maintained on a secure server within the Division of Blood Disorders at the CDC. Patient identifying information, including name, address, physician, and insurance carrier, remained within a locally housed secure database at each center. For purposes of confidentiality, only the study identification number and registry information were sent to the registry at the CDC. The registry, study protocol, and other study materials are approved annually by the Institutional Review Boards at each of the participating sites and at the CDC.

The registry began patient enrollment in August 2003. For this study, the population was consenting, self-identified White- and Black-American adults of non-Hispanic or non-multiracial ethnicity with objectively

The findings and conclusions in this report are those of the authors and do not necessarily represent the views of the Centers for Disease Control and Prevention.

${ }^{1}$ Mayo Clinic Thrombophilia Center, Mayo Clinic, Rochester, Minnesota; ${ }^{2}$ Division of Blood Disorders, NCBDDD, Centers for Disease Control and Prevention (CDC), Atlanta, Georgia; ${ }^{3}$ University of Michigan Hemophilia and Coagulation Disorders Program, Ann Arbor, Michigan; ${ }^{4}$ Thrombophilia Program, UNC, Chapel Hill, North Carolina; ${ }^{5}$ Michigan State University Comprehensive Center for Bleeding Disorders, East Lansing, Michigan; ${ }^{6}$ Mountain States Regional Hemophilia and Thrombosis Center, Aurora, Colorado; ${ }^{7}$ Duke Hemostasis and Thrombosis Center, Duke University Medical Center, Durham, North Carolina; ${ }^{8}$ Thrombosis Center, UMDNJRobert Wood Johnson Medical School, New Brunswick, New Jersey

Contract grant sponsor: Centers for Disease Control and Prevention; Contract grant numbers: PA DD07-004, PA DD07-005; Contract grant sponsor: U.S. Public Health Service.

Conflict of interest: Nothing to report.

*Correspondence to: John A. Heit, Stabile 6-Hematology Research, Mayo Clinic, 200 First Street, SW, Rochester, MN 55905.

E-mail: heit.john@mayo.edu

Received for publication 7 February 2010; Revised 5 April 2010; Accepted 9 April 2010

Am. J. Hematol. 85:467-471, 2010.

Published online 13 April 2010 in Wiley InterScience (www.interscience.wiley. com).

DOI: $10.1002 / a j h .21735$ 
TABLE I. Distribution of Patients with Venous Thromboembolism by Center and Race

\begin{tabular}{lrrr}
\hline Center & White & Black & Total \\
\hline UMDNJ-Robert Wood Johnson & 199 & 34 & 233 \\
UNC-Chapel Hill & 367 & 56 & 423 \\
Duke University Medical Center & 613 & 240 & 853 \\
Michigan State University & 165 & 3 & 168 \\
Wayne State University & 21 & 8 & 29 \\
University of Michigan, Ann Arbor & 402 & 24 & 426 \\
Mountain States Regional HTC & 235 & 30 & 265 \\
Total & 2,002 & 395 & 2,397 \\
\hline
\end{tabular}

TABLE II. Distribution of Venous Thromboembolism Event Type by Race

\begin{tabular}{lrrrr}
\hline Event type & $\begin{array}{c}\text { White } \\
(n=2,002)\end{array}$ & $\begin{array}{c}\text { Black } \\
(n=395)\end{array}$ & $\begin{array}{c}\text { Total } \\
(n=2,397)\end{array}$ & $P$-value \\
\hline DVT only & $1,171(58.5)$ & $205(51.9)$ & $1,376(57.4)$ & 0.02 \\
PE only & $288(14.4)$ & $109(27.6)$ & $397(16.6)$ & $<0.0001$ \\
PE + DVT & $543(27.1)$ & $81(20.5)$ & $624(26.0)$ & 0.006 \\
DVT & $1,714(85.6)$ & $286(72.4)$ & $2,000(83.4)$ & $<0.0001$ \\
PE & $831(41.5)$ & $190(48.1)$ & $1,021(42.6)$ & 0.02 \\
\hline
\end{tabular}

diagnosed DVT and/or PE who were enrolled at one of the seven centers from August 2003 to March 2009, and for whom registry data were available. A DVT was categorized as objectively diagnosed when symptoms or signs of acute DVT were present, and the diagnosis was confirmed by venography, compression venous duplex ultrasonography, impedance plethysmography, computed tomographic venography, or magnetic resonance imaging. A PE was categorized as objectively diagnosed when symptoms and/or signs of acute PE were present, and the diagnosis was confirmed by pulmonary angiography, a ventilation/perfusion lung scan interpreted as high probability for PE, computed tomographic pulmonary angiography, or magnetic resonance imaging.

Using a cross-sectional study design, we queried the CDC registry for demographic and clinical characteristic data collected at the initial visit for each patient age 18 years or older at enrollment and compared these data among Whites and Blacks.

\section{Measurements}

Data collected at the initial visit included patient demographic and clinical characteristics, referral patterns, reasons for and details of the visit (including providers seen, concurrent medical and lifestyle conditions, laboratory and radiological tests ordered, educational materials received), diagnoses, and treatments prescribed.

\section{Analyses}

For patients with objectively diagnosed VTE, demographic, baseline, and clinical characteristics were compared among White- and BlackAmerican patients, age 18 and older, both overall, and by age and gender. All analyses were performed using SAS 9.2 (SAS, Institute Cary, $\mathrm{NC})$. For categorical variables of interest, univariate frequencies were generated to calculate the prevalence and compared using Pearson's $\chi^{2}$ and two-tailed $P$-values, and in the case of small cell sizes $(\leq 5)$, two-tailed Fisher's exact $P$-values are reported. For continuous variables, mean values were computed and differences were tested using Student's $t$-test.

\section{Definition of variables}

The presence of medical comorbidities was defined as the patient having the condition within the 3 months prior to the VTE event. The presence of thrombophilia was defined by diagnosis of an inherited or acquired thrombophilia (factor V Leiden, prothrombin G20210A mutation, antiphospholipid syndrome, antithrombin, protein $\mathrm{C}$ or protein $\mathrm{S}$ deficiency) at baseline or after subsequent evaluation by a CDC Thrombosis and Hemostasis Research and Prevention Center. For all patients with antiphospholipid antibodies and for most patients with an inherited thrombophilia, the presence of thrombophilia was confirmed by laboratory testing performed at a CDC Center. The updated Sapporo criteria [20] were used for diagnosis of antiphospholipid syndrome. "Idiopathic" VTE was defined as VTE in the absence of recent surgery, trauma, infection, pregnancy or postpartum period, oral contraceptive use or hormone therapy; active cancer; or HIV.

To assess potential referral bias, the distance from patient residence to Network center was compared among White- and Black-American
TABLE III. Distribution of Deep Vein Thrombosis by Vein Locationa and Race

\begin{tabular}{lcccc}
\hline Vein location & $\begin{array}{c}\text { White } \\
(n=1,714)\end{array}$ & $\begin{array}{c}\text { Black } \\
(n=286)\end{array}$ & $\begin{array}{c}\text { Total } \\
(n=2,000)\end{array}$ & $P$-value \\
\hline Cerebral & $52(3.0)$ & $7(2.5)$ & $59(3.0)$ & 0.59 \\
Retinal & $26(1.5)$ & $3(1.1)$ & $29(1.5)$ & 0.79 \\
Jugular & $31(1.8)$ & $11(3.9)$ & $42(2.1)$ & 0.02 \\
Arm & $188(11.0)$ & $41(14.3)$ & $229(11.5)$ & 0.10 \\
Superior vena cava & $12(0.7)$ & $2(0.7)$ & $14(0.7)$ & 1.0 \\
Inferior vena cava & $25(1.5)$ & $4(1.4)$ & $29(1.5)$ & 1.0 \\
Hepatic, portal, mesenteric & $99(5.8)$ & $16(5.6)$ & $115(5.8)$ & 0.90 \\
Renal & $26(1.5)$ & $1(0.4)$ & $27(1.4)$ & 0.16 \\
Abdomen & $138(8.1)$ & $23(8.0)$ & $161(8.1)$ & 1.0 \\
Leg & $1,362(79.5)$ & $217(75.9)$ & $1,579(79.0)$ & 0.17 \\
\hline
\end{tabular}

${ }^{\text {a }}$ Not mutually exclusive

${ }^{\mathrm{b}}$ Hepatic, portal, mesenteric, renal, and pelvic.

patients with VTE, both overall and by center. Distances represent miles from the centroid of the home residence zip code to the centroid of the Center's zip code. Mean distance was calculated and then compared between the groups using Student's $t$-test.

\section{Results}

Of the 4,831 patients with nonbleeding disorders enrolled in the CDC Registry from August 2003 to March 2009, 3,879 were of age 18 years or older upon enrollment and self-identified as White- or Black-American of non-Hispanic or nonmultiracial ancestry. Of these, 2,397 had at least one objectively diagnosed VTE event; 2,002 were White- and 395 were Black-Americans. The distribution of White- and BlackAmerican VTE cases by center is shown in Table I.

The mean \pm SD (range) age among Whites and Blacks with VTE at enrollment did not differ significantly (47.7 \pm $15.7[18,91]$ vs. $46.1 \pm 15.6[18,86]$ years). When compared with Whites, a significantly higher proportion of Blacks were of female gender $(70.6 \%$ vs. $60.6 \% ; P=$ $0.0002)$. The mean body mass index was higher among Blacks (32.9 kg/m² vs. $\left.29.9 \mathrm{~kg} / \mathrm{m}^{2} ; P<0.0001\right)$.

When compared with Whites, Blacks had a significantly lower proportion with DVT and a significantly higher proportion with PE (Table II). Otherwise, the distribution of DVT by vein location did not differ significantly by race (Table III). The mean \pm SD total number of VTE events was marginally but significantly greater among Whites (1.57 \pm 1.03 vs. $1.46 \pm 0.89 ; P=0.03$ ) but did not differ significantly among White versus Black women or men. The percentage of Whites and Blacks with recurrent VTE also did not differ significantly $(34.9 \%$ vs. $30.7 \% ; P=0.11)$. The mean \pm SD ages at first VTE, DVT, and PE were not significantly different by race or by gender within race.

Among baseline characteristics previously identified as VTE risk factors, when compared with Whites, Blacks had a significantly lower proportion with recent surgery, trauma or infection, and a significantly higher proportion with HIV and sickle cell disease (Table IV). Among women, Black women had a significantly lower proportion with recent oral contraceptive use when compared with White women. Among women $\geq 40$ years of age, Black women had a significantly lower proportion with recent hormone therapy. The proportion of patients with active cancer or autoimmune disease did not differ by race. Among all patients with VTE, Blacks had a significantly lower proportion with a family history of VTE and with a diagnosed thrombophilia. However, the lower proportion of thrombophilia among Blacks was almost solely due to the virtual absence of the factor V Leiden and prothrombin G20210A mutations (Table V). The proportion with antiphospholipid syndrome and deficiency of antithrombin, protein $\mathrm{C}$, and protein $\mathrm{S}$ did not differ significantly by race. Although the proportion with idiopathic VTE did not differ by race, Blacks had significantly 
TABLE IV. Distribution of Venous Thromboembolism Risk Factors by Race

\begin{tabular}{|c|c|c|c|c|}
\hline Characteristic & $\begin{array}{c}\text { White } \\
(n=2,002)\end{array}$ & $\begin{array}{c}\text { Black } \\
(n=395)\end{array}$ & Total & $P$-value \\
\hline Postsurgery & $226(11.3)$ & $22(5.6)$ & $248(10.4)$ & 0.0006 \\
\hline Trauma & $109(5.4)$ & $8(2.0)$ & $117(4.9)$ & 0.006 \\
\hline Cancer & $216(10.8)$ & $45(11.4)$ & $261(10.9)$ & 0.73 \\
\hline Infection & $51(2.6)$ & $2(0.5)$ & $53(2.2)$ & 0.01 \\
\hline HIV infection & $2(0.1)$ & $10(2.5)$ & $12(0.5)$ & $<0.0001$ \\
\hline Sickle cell disease & 0 & $12(3.0)$ & $12(0.5)$ & $<0.0001$ \\
\hline Autoimmune disease $^{a}$ & $299(14.9)$ & $60(15.2)$ & $359(15.0)$ & 0.90 \\
\hline Oral contraceptive use ${ }^{b}$ & $156(12.9)$ & $17(6.1)$ & $173(11.6)$ & 0.002 \\
\hline Hormone therapy ${ }^{\mathrm{b}}$ & $35(2.9)$ & $2(0.7)$ & $37(2.5)$ & 0.03 \\
\hline Thrombophilia $^{c}$ & $604(30.2)$ & $56(14.2)$ & $660(27.5)$ & $<0.0001$ \\
\hline Family history of VTE & $240(12.0)$ & $22(5.6)$ & $262(10.9)$ & 0.0002 \\
\hline Idiopathic VTE & $1,381(69.0)$ & $272(68.9)$ & $1,653(69.0)$ & 0.96 \\
\hline Idiopathic DVT & $1,188(59.3)$ & $196(49.6)$ & $1,390(58.0)$ & 0.003 \\
\hline Idiopathic PE & $580(29.0)$ & 135 (34.2) & $715(29.8)$ & 0.04 \\
\hline
\end{tabular}

a Autoimmune disease includes patients with systemic lupus erythematosus, rheumatoid arthritis, inflammatory bowel disease, and hypothyroidism.

${ }^{\mathrm{b}}$ Among women only ( $n=1,214$ White, 279 Black).

c Thrombophilia includes factor V Leiden or prothrombin G20210A mutations, deficiency of antithrombin, protein $\mathrm{C}$ or protein $\mathrm{S}$, or antiphospholipid syndrome.

TABLE V. Distribution of Inherited and Acquired Thrombophilia by Race

\begin{tabular}{lcccc}
\hline Thrombophilia & $\begin{array}{c}\text { White } \\
(n=2,002)\end{array}$ & $\begin{array}{c}\text { Black } \\
(n=395)\end{array}$ & $\begin{array}{c}\text { Total } \\
(n=2,397)\end{array}$ & $P$-value \\
\hline Antithrombin deficiency & $15(0.8)$ & $3(0.8)$ & $18(0.8)$ & 1.0 \\
Protein C deficiency & $29(1.5)$ & $6(1.5)$ & $35(1.5)$ & 0.92 \\
Protein S deficiency & $50(2.5)$ & $15(3.8)$ & $65(2.7)$ & 0.15 \\
Factor V Leiden & $293(14.7)$ & $6(1.5)$ & $299(12.5)$ & $<0.0001$ \\
Prothrombin G20210A & $72(3.6)$ & $1(0.3)$ & $73(3.1)$ & 0.0004 \\
Antiphospholipid syndrome & $213(10.6)$ & $32(8.1)$ & $245(10.2)$ & 0.13 \\
\hline
\end{tabular}

lower and higher proportions of idiopathic DVT and idiopathic PE, respectively (Table IV).

Among other clinical characteristics, when compared with Whites, Blacks had a significantly higher proportion with hypertension, diabetes mellitus, and chronic renal disease and dialysis (Table VI). The two groups did not differ significantly regarding the proportion with stroke, cerebral palsy, coronary artery disease/myocardial infarction, congenital heart disease, congestive heart failure, peripheral artery disease, or chronic liver disease.

When compared with White women, the distribution of VTE risk factors among Black women varied significantly, with Black women having a significantly lower proportion with recent surgery, trauma or infection, and a significantly higher proportion with HIV infection and sickle cell disease (Table VII). Black women had a significantly higher proportion of idiopathic PE and a significantly lower proportion of idiopathic DVT. When compared with White men, Black men did not differ significantly regarding recent surgery, trauma, cancer, infection, or autoimmune disease (Table VII); Black men did have a significantly higher proportion with HIV infection and sickle cell disease. The proportion with idiopathic VTE, DVT, or PE did not differ by race among men.

Overall, the mean distance from patient residence to center address (as reflected by ZIP code) was significantly greater for Whites (55.0 miles, range $=0-3,461$ miles) when compared with Blacks (31.6 miles, range $=0-260$ miles; $P<0.0001$ ). For five of the seven centers, the mean distance from patient residence to the center address was significantly greater for White patients with VTE when compared with Black patients with VTE and not significantly different for the other two centers (Table VIII). When analyzed for distances of $>30,>50$, and $>75$ miles from patient resi-
TABLE VI. Distribution of Other Baseline Characteristics by Race

\begin{tabular}{lcccc}
\hline Characteristic & $\begin{array}{c}\text { White } \\
(n=2,002)\end{array}$ & $\begin{array}{c}\text { Black } \\
(n=395)\end{array}$ & $\begin{array}{c}\text { Total } \\
(n=2,397)\end{array}$ & $P$-value \\
\hline Stroke & $104(5.2)$ & $25(6.3)$ & $129(5.4)$ & 0.36 \\
Cerebral palsy & $2(0.1)$ & 0 & $2(0.1)$ & 1.0 \\
Coronary artery disease & $97(4.9)$ & $24(6.1)$ & $121(5.1)$ & 0.31 \\
Congenital heart disease & $14(0.7)$ & $4(1.0)$ & $18(0.8)$ & 0.52 \\
Prosthetic heart valve & $8(0.4)$ & $7(1.8)$ & $15(0.6)$ & 0.006 \\
Congestive heart failure & $26(1.3)$ & $8(2.0)$ & $34(1.4)$ & 0.26 \\
Peripheral artery disease & $26(1.3)$ & $5(1.3)$ & $31(1.3)$ & 1.0 \\
Hypertension & $398(19.9)$ & $150(38.0)$ & $548(22.9)$ & $<0.0001$ \\
Hyperlipidemia & $282(14.1)$ & $50(12.7)$ & $332(13.9)$ & 0.45 \\
Diabetes mellitus & $136(6.8)$ & $54(13.7)$ & $190(7.9)$ & $<0.0001$ \\
Liver disease & $22(1.1)$ & $8(2.0)$ & $30(1.3)$ & 0.14 \\
Renal disease & $71(3.6)$ & $30(7.6)$ & $101(4.2)$ & 0.0003 \\
Dialysis & $14(0.7)$ & $10(2.5)$ & $24(1.0)$ & 0.003 \\
\hline
\end{tabular}

dence to center address, the proportion by center for each distance was either significantly greater for White patients with VTE or not significantly different when compared with Black patients with VTE (data not shown).

\section{Discussion}

The important findings of our study are that when compared with White patients with VTE, Blacks with VTE had a lower proportion with transient VTE risk factors (i.e., less recent surgery, trauma and infection; and among women, less recent oral contraceptive use and hormone therapy) and a higher proportion with idiopathic PE. Our findings are similar to those of the Genetic Attributes and Thrombosis Epidemiology (GATE) study, a case-control study of risk factors for VTE among White- and African-Americans in which Blacks were more likely to have VTE unrelated to cancer, or recent surgery or immobilization [6].

Our finding of an increased prevalence of idiopathic PE among Black women is supported by previous work showing a higher incidence of idiopathic PE among Blacks when compared with Whites [8]. Given the poor survival after PE, [21] our finding of an increased prevalence of PE among Blacks (particularly idiopathic PE) is disturbing, especially when coupled with previous reports of increased complications after VTE and higher PE case fatality among Blacks $[8,9,22,23]$

Also similar to previous studies, $[6,17,18]$ we found a very low prevalence of factor $\mathrm{V}$ Leiden and prothrombin G20210A carriers among Blacks with VTE. Although we found other potential VTE risk factors such as sickle cell trait and disease, [24] HIV-infection [25], and anticardiolipin antibodies [26] to be higher among Blacks when compared with Whites, the prevalence of these disorders among Blacks was low and insufficient to account for the reported higher VTE incidence among Blacks [5,8-10]. Blacks had a higher BMI and a higher prevalence of hypertension, diabetes mellitus, and chronic renal disease (including hemodialysis), but the association of these characteristics with VTE is uncertain $[3,5,27]$.

Our findings do not support the hypothesis that the higher VTE incidence among Blacks is due to an increased prevalence of known VTE risk factors. However, we cannot exclude the possibility of as yet unidentified environmental and/or social risks factors in the etiology of VTE among Black-Americans. For many prevalent health conditions, Black-Americans suffer a disproportionate burden of disease including higher incidence, morbidity, and mortality when compared with White-Americans [28]. The higher prevalence of PE among Black-American women in our study may reflect health disparities in VTE as well, including the social factors of access to care and delayed identification of DVT. Alternatively, the biology of VTE among Blacks may increase the proportion 


\begin{tabular}{|c|c|c|c|c|c|c|}
\hline \multirow[b]{2}{*}{ Characteristic } & \multicolumn{3}{|c|}{ Female } & \multicolumn{3}{|c|}{ Male } \\
\hline & White $(n=1,214)$ & Black $(n=279)$ & $P$-value & White $(n=788)$ & Black $(n=116)$ & $P$-value \\
\hline Postsurgery & $140(11.5)$ & $13(4.7)$ & 0.0006 & $86(10.9)$ & $9(7.8)$ & 0.30 \\
\hline Trauma & $55(4.5)$ & $3(1.1)$ & 0.007 & $54(6.9)$ & $5(4.3)$ & 0.30 \\
\hline Cancer & $123(10.1)$ & $26(9.3)$ & 0.68 & $93(11.8)$ & $19(16.4)$ & 0.16 \\
\hline Infection & $33(2.7)$ & $1(0.4)$ & 0.02 & $18(2.3)$ & $1(0.9)$ & 0.50 \\
\hline HIV infection & $1(0.1)$ & $6(2.2)$ & 0.0002 & $1(0.1)$ & $3(3.5)$ & 0.0012 \\
\hline Autoimmune disease & 217 (17.9) & 47 (16.9) & 0.68 & $82(10.4)$ & $13(11.2)$ & 0.79 \\
\hline Sickle cell disease & 0 & $10(3.6)$ & $<0.0001$ & 0 & $2(1.7)$ & 0.02 \\
\hline Idiopathic VTE & $774(63.8)$ & $184(66.0)$ & 0.50 & $607(77.0)$ & $88(75.9)$ & 0.78 \\
\hline Idiopathic DVT & 659 (54.3) & $130(46.6)$ & 0.02 & $529(67.1)$ & $72(62.1)$ & 0.28 \\
\hline Idiopathic PE & $298(24.6)$ & $88(31.5)$ & 0.02 & $282(35.8)$ & $47(40.5)$ & 0.32 \\
\hline
\end{tabular}

TABLE VIII. Mean Distance from Patient Residence to Center by ZIP Code

\begin{tabular}{lrrr}
\hline & \multicolumn{2}{c}{$\begin{array}{c}\text { Mean distance } \\
\text { (miles) }\end{array}$} & \\
\cline { 2 - 3 } Center & White & Black & P-value \\
\hline UMDNJ-Robert Wood Johnson & 28.5 & 12.3 & 0.20 \\
UNC-Chapel Hill & 83.4 & 44.3 & 0.002 \\
Duke University Medical Center & 70.0 & 33.9 & $<0.0001$ \\
Michigan State University & 20.6 & 6.9 & 0.0007 \\
Wayne State University & 30.4 & 7.5 & 0.02 \\
University of Michigan, Ann Arbor & 43.4 & 39.0 & 0.61 \\
Mountain States Regional HTC & 40.0 & 14.1 & 0.001 \\
\hline
\end{tabular}

of VTE events that present clinically as PE when compared with Whites.

Despite the rarity of known genetic risk factors among Black-Americans, [29-34] our findings suggest that a genetic component may exist in the etiology of VTE among Blacks. In support of this hypothesis, the plasma levels of several procoagulant and anticoagulant factors both vary by race [35-38] and exhibit substantial heritability [39-43]. When compared with Whites, Blacks have higher levels of fibrinogen, $[35,36,38]$ factor VIII, $[37,38,44]$ von Willebrand factor $[37,38,44]$, and plasma fibrin D-dimer $[38,45,46]$, and lower levels of protein C [36]. Moreover, among Blacks, VTE has been associated with increased levels of fibrinogen, [29] factor VIII [47], and plasma fibrin D-dimer [48]. Although the lower prevalence of a family history of VTE among Blacks when compared with Whites might argue against a heritable component, this observation could also be explained by the frequent incomplete penetrance of inherited thrombophilia [14,49-51].

Our study has important limitations. As there was no control group, we cannot test the characteristics measured in this study as potential VTE risk factors by race. Moreover, as our study was not population based, our findings may not represent the full spectrum of VTE disease occurring in the community. For example, because patients had to live sufficiently long to reach a center, rapidly fatal VTE (and especially fatal PE) cases are under represented as are patients with VTE in chronic care facilities. In addition, each of the seven centers did not contribute equally to the study population. Thus, the findings may be skewed by the one or possibly two centers contributing the most patients to the registry. Finally, we cannot exclude referral bias. In fact, the characteristics of the two racial groups in this study likely do not reflect those of the community. When compared with the population-based studies of predominantly Whites of non-Hispanic ancestry, Whites in this study were younger and had a lower proportion with recent surgery $(11.3 \%$ vs. $23.8 \%$ ), active cancer (10.8\% vs. $18.9 \%)$, and trauma (5.4\% vs. 12\%), [3] and a higher proportion with oral contraceptive use $(12.9 \%$ vs. $8.1 \%$; Barsoum et al., submitted) and idiopathic VTE $(72.8 \%$ vs. $<25 \%$ [52]) The mean age of Blacks at first VTE in this study (41.5 years) was also lower when compared with the age of Black patients with VTE in the GATE study (47.5 years; Ref. 6) and the 1996 California Patient Discharge Data Set (58 years; Ref. 8), suggesting potential referral bias among Blacks in our study as well. However, at least based on the distance from patient residence to Center address, there is no reason to expect that referral bias was greater among Blacks when compared with Whites. Although inability of Blacks to travel similar distances as Whites could also account for this observation, such an explanation would make Blacks less likely to be referred compared to Whites.

\section{Conclusions}

Despite these limitations, the prevalence of common transient or acquired risk factors (i.e., recent surgery, trauma, infection) appears to be lower among AfricanAmerican patients with VTE, while the prevalence of idiopathic VTE (especially idiopathic PE) appears to be higher. We believe these findings support the hypothesis that heritability plays a significant role in the etiology of VTE among Black-Americans. As the carrier frequencies of the two most common inherited polymorphisms associated with VTE (i.e., factor V Leiden, prothrombin G20210A) are extremely low among Black-Americans, we also hypothesize that other as yet unrecognized inherited polymorphisms are associated with VTE in blacks. Such polymorphisms could give important insights into as yet unrecognized pathways that are associated with VTE.

\section{Acknowledgments}

The funding organization CDC participated in the design and conduct of the study; collection, management, analysis, and interpretation of the data; and preparation, review, and approval of the manuscript.

\section{References}

1. Anderson F, Wheeler H, Goldberg R, et al. Physician practices in the prevention of venous thromboembolism. Ann Int Med 1991;115:591-595.

2. Cogo A, Bernardi E, Prandoni $P$, et al. Acquired risk factors for deep-vein thrombosis in symptomatic outpatients. Arch Int Med 1994;154:164-168.

3. Heit J, Silverstein M, Mohr D, et al. Risk factors for deep vein thrombosis and pulmonary embolism: A population-based case-control study. Arch Int Med 2000;160:809-815.

4. Samama M-M. An epidemiologic study of risk factors for deep vein thrombosis in medical outpatients. Arch Int Med 2000;160:3415-3420.

5. Tsai A, Cushman M, Rosamond W, et al. Cardiovascular risk factors and venous thromboembolism incidence. Arch Int Med 2002;162:1182-1189.

6. Dowling $\mathrm{N}$, Austin $\mathrm{H}$, Dilley $\mathrm{A}$, et al. The epidemiology of venous thromboembolism in Caucasians and African-Americans: The GATE Study. J Thromb Haemost 2003;1:80-87.

7. White R, Zhou H, Romano P. Incidence of idiopathic deep venous thrombosis and secondary thromboembolism among ethnic groups in California. Ann Int Med 1998;128:737-740.

8. White R, Zhou H, Murin S, et al. Effect of ethnicity and gender on the incidence of venous thromboembolism in a diverse population in California in 1996. Thromb Haemost 2005;93:298-305.

9. Schneider D, Lilienfeld D, Im W. The epidemiology of pulmonary embolism: Racial contrasts in incidence and in-hospital case fatality. J Natl Med Assoc 2006;98:1967-1972. 
10. Keenan $\mathrm{C}$, White $\mathrm{R}$. The effects of race/ethnicity and sex on the risk of venous thromboembolism. Curr Opin Pulm Med 2007;13:377-383.

11. Koster $\mathrm{T}$, Rosendaal $\mathrm{F}$, de Ronde $\mathrm{H}$, et al. Venous thrombosis due to poor anticoagulant response to activated protein C: Leiden Thrombophilia Study. Lancet 1993;342:1503-1506.

12. Svensson P, Dahlbäck B. Resistance to activated protein $C$ as a basis of venous thrombosis. N Engl J Med 1994;330:517-522.

13. Ridker P, Hennekens C, Selhub J. Interrelation of hyperhomocyst (e) inemia, factor $\mathrm{V}$ Leiden, and risk of future venous thromboembolism. Circulation 1997;95:1777-1782.

14. Heit J, Sobell J, Li H, et al. The incidence of venous thromboembolism among Factor V Leiden carriers: A community-based cohort study. J Thromb Haemost 2005;3:305-311.

15. Poort S, Rosendaal F, Reitsma P, et al. A common genetic variation in the $3^{\prime}$ untranslated region of the prothrombin gene is associated with elevated plasma prothrombin levels and an increase in venous thrombosis. Blood 1996;88:3698-3703.

16. Margaglione $\mathrm{M}$, Brancaccio $\mathrm{V}$, Giuliani $\mathrm{N}$, et al. Increased risk for venous thrombosis in carriers of the prothrombin $\mathrm{G} \rightarrow \mathrm{A} 20210$ gene variant. Ann Int Med 1998;129:89-93.

17. Hooper W, Dilley A, Ribeiro M, et al. A racial difference in the prevalence of the Arg506 $\rightarrow$ GIn mutation. Thromb Res 1996;81:577-581.

18. Dilley A, Austin H, Hooper W, et al. Prevalence of the prothrombin 20210 G-toA variant in blacks: Infants, patients with venous thrombosis, patients with myocardial infarction, and control subjects. J Lab Clin Med 1998;132:452-455.

19. Dowling N, Beckman M, Manco-Johnson M, et al. The U.S. Thrombosis and Hemostasis Centers pilot sites program. J Thromb Thrombolysis 2007;23:1-7.

20. Miyakis S, Lockshin M, Atsumi T, et al. International consensus statement on an update of the classification criteria for definite antiphospholipid syndrome (APS). J Thromb Haemost 2006;4:295-306.

21. Heit J, Silverstein M, Mohr D, et al. Predictors of survival after deep vein thrombosis and pulmonary embolism: A population-based, cohort study. Arch Int Med 1999;159:445-453.

22. Aujesky D, Long J, Fine M, et al. African American race was associated with an increased risk of complications following venous thromboembolism. J Clin Epidemiol 2007:60:410-416.

23. Stein $P$, Kayali F, Olson RE. Estimated case fatality rate of pulmonary embolism, 1979 to 1998. Am J Cardiol 2004;93:1197-1199.

24. Austin $\mathrm{H}$, Key $\mathrm{N}$, Benson $\mathrm{J}$, et al. Sickle cell trait and the risk of venous thromboembolism among blacks. Blood 2007;110:908-912.

25. Copur A, Smith P, Gomez V, et al. HIV infection is a risk factor for venous thromboembolism. AIDS Patient Care STDS 2002;16:205-209.

26. Ginsburg K, Liang M, Newcomer L, et al. Anticardiolipin antibodies and the risk for ischemic stroke and venous thrombosis. Ann Int Med 1992;117:9971002

27. Heit J, Leibson C, Ashrani A et al. Is diabetes mellitus an independent risk factor for venous thromboembolism?: A population-based case-control study. Arterioscler Thromb Vasc Biol 2009;29:1399-1405.

28. Center for Disease Control and Prevention C. Health disparities experienced by black or African Americans-United States. MMWR Morb Mortal Wkly Rep 2005;54:1-3.

29. Austin H, Hooper W, Lally $\mathrm{C}$, et al. Venous thrombosis in relation to fibrinogen and factor VII genes among African-Americans. J Epidemiol 2000;53:9971001.

30. Dilley A, Austin H, Hooper W, et al. Relation of three genetic traits to venous thrombosis in an African-American population. Am $\mathrm{J}$ Epidemiol 1998;147:30-35.

31. Dilley A, Hooper W, El-Jamil M, et al. Mutations in the genes regulating methylene tetrahydrofolate reductase (MTHFR $\mathrm{C} \rightarrow$ T677) and cystathione beta- synthase (CBS $\mathrm{G} \rightarrow \mathrm{A} 919$, CBS $\mathrm{T} \rightarrow \mathrm{C} 833$ ) are not associated with myocardial infarction in African Americans. Thromb Res 2001;130:109-115.

32. Hooper W, Dilley A, Austin H, et al. Absence of mutations at APC cleavage sites Arg306 in factor V and Arg336, Arg562 in factor VIII in African-Americans. Thromb Haemost 1998;79:236.

33. Hooper W, Lally C, Austin $\mathrm{H}$, et al. The relationship between polymorphisms in the endothelial cell nitric oxide synthase gene and the platelet GPIIla gene with myocardial infarction and venous thromboembolism in African Americans. Chest 1999;116:880-886.

34. Hooper W, Lally C, Austin H, et al. The role of the t-PA I/D and PAI-1 4G/5G polymorphisms in African-American adults with a diagnosis of myocardial infarction or venous thromboembolism. Thromb Res 2000;99:223-230.

35. Folsom A, Wu K, Davis C, et al. Population correlates of plasma fibrinogen and factor VII, putative cardiovascular risk factors. Atherosclerosis 1991;91: 191-205.

36. Folsom A, Wu K, Conlan $\mathrm{M}$, et al. Distributions of hemostatic variables in blacks and whites: Population reference values from the Atherosclerosis Risk in Communities (ARIC) Study. Ethn Dis 1992;2:35-46.

37. Conlan M, Folsom A, Finch A, et al. Associations of factor VIII and von Willebrand factor with age, race, sex, and risk factors for atherosclerosis. The Atherosclerosis Risk in Communities (ARIC) Study. Thromb Haemost 1993;70: 380-385.

38. Lutsey P, Cushman M, Steffen L, et al. Plasma hemostatic factors and endothelial markers in four racial/ethnic groups: The MESA study. J Thromb Haemost 2006;4:2629-2635.

39. Souto J, Almasy L, Borrell M, et al. Genetic susceptibility to thrombosis and its relationship to physiological risk factors: The GAIT study. Genetic Analysis of Idiopathic Thrombophilia. Am J Hum Genet 2000:67:1452-1459.

40. de Lange M, Snieder H, Ariens R, et al. The genetics of haemostasis: A twin study. Lancet 2001;357:101-105.

41. Ariëns $R$, de Lange $M$, Snieder $H$, et al Activation markers of coagulation and fibrinolysis in twins: Heritability of the prethrombotic state. Lancet 2002; 359:667-671.

42. Peetz D, Victor A, Adams $P$, et al. Genetic and environmental influences on the fibrinolytic system: A twin study. Thromb Haemost 2004;92:344-351.

43. Bladbjerg E, de Maat M, Christensen K, et al. Genetic influence on thrombotic risk markers in the elderly-A Danish twin study. J Thromb Haemost 2006;4 599-607.

44. Dowling N, Lally C, Miller C, et al. Associations of Factor VIII (FVIII) and von Willebrand Factor Antigen (VWF:Ag) with race, age, $\mathrm{ABO}$ blood group and co-morbid conditions. J Thromb Haemost 2005;3(Suppl 1):PO649.

45. Pieper C, Rao K, Currie M, et al. Age, functional status, and racial differences in plasma D-dimer levels in community-dwelling elderly persons. J Gerontol Ser A: Biol Sci Med Sci 2000;55:M649-M657.

46. Lange L, Reiner A, Carty C, et al. Common genetic variants associated with plasma fibrin D-dimer concentration in older European- and African-American adults. J Thromb Haemost 2008:6:654-659.

47. Patel R, Ford E, Thumpston J, et al. Risk factors for venous thrombosis in the black population. Thromb Haemost 2003;90:835-838.

48. Patel R, Ford E, Thumpston J, et al. Coagulation factor levels and venous thrombosis in the black population. Thromb Haemost 2004:91:828-830.

49. Miletich J, Sherman L, Broze GJ. Absence of thrombosis in subjects with het erozygous protein C deficiency. N Engl J Med 1987;317:991-996.

50. Tait R, Walker I, Reitsma $P$, et al. Prevalence of protein $C$ deficiency in the healthy population. Thromb Haemost 1995;73:87-93.

51. van Sluis G, Sohne M, El Kheir D, et al. Family history and inherited thrombo philia. J Thromb Haemost 2006;4:2182-2187.

52. Heit J, O'Fallon W, Petterson T, et al. Relative impact of risk factors for deep vein thrombosis and pulmonary embolism: A population-based study. Arch Int Med 2002;162:1245-1248. 